\title{
Association of Systemic Inflammation and Overall Survival in Elderly Patients with Cancer Cachexia - Results from a Multicenter Study
}

\author{
Guo-Tian Ruan, ${ }^{1-3, *}$ \\ Ming Yang, ${ }^{1-3, *}$ Xiao- \\ Wei Zhang, ${ }^{1-3, *}$ Meng- \\ Meng Song, ${ }^{1-3}$ Chun-Lei Hu, ${ }^{1-3}$ \\ Yi-Zhong Ge, ${ }^{1-3}$ Hai-Lun Xie, ${ }^{1-3}$ \\ Tong Liu, ${ }^{1-3}$ Meng Tang, ${ }^{\text {I-3 }}$ \\ Qi Zhang, ${ }^{\text {I-3 }}$ Xi Zhang, ${ }^{\text {I-3 Kang- }}$
} Ping Zhang, ${ }^{1-3}$ Xiang-Rui Li, ${ }^{1-3}$ Qin-Qin Li, ${ }^{\mathrm{I}}$ YongBing Chen, ${ }^{1-3}$ Kai-Ying Yu, ${ }^{1-3}$ Ming-Hua Cong, ${ }^{4}$ KunHua Wang, ${ }^{5}$ Han-Ping Shi $\mathbb{D}^{1-3}$

'Department of Gastrointestinal Surgery, Beijing Shijitan Hospital, Capital Medical University, Beijing, 100038, People's Republic of China; ${ }^{2}$ Department of Clinical Nutrition, Beijing Shijitan Hospital, Capital Medical University, Beijing, 100038, People's Republic of China; ${ }^{3}$ Beijing International Science and Technology Cooperation Base for Cancer Metabolism and Nutrition, Beijing, I00038, People's Republic of China; ${ }^{4}$ Comprehensive Oncology Department, National Cancer Center/Cancer Hospital, Chinese Academy of Medical Sciences and Peking Union Medical College, Beijing, 100038, People's Republic of China; ${ }^{5}$ Department of Surgery, The First Affiliated Hospital of Kunming Medical University, Kunming, 650000, People's Republic of China

*These authors contributed equally to this work

Correspondence: Han-Ping Shi Department of Gastrointestinal Surgery and Beijing Shijitan Hospital, Capital Medical University, 10 Tie Yi Road, Beijing, 100038, People's Republic of China

Tel +86-10- 63926985

Fax +86-10 -6392 6325

Email shihp@ccmu.edu.cn
Background: Systemic inflammation and cachexia are associated with adverse clinical outcomes in elderly patients with cancer. The survival outcomes of elderly patients with cancer cachexia (EPCC) with high inflammation and a high risk of mortality are unknown. This study aimed to investigate the impact of high inflammation on the prognosis of EPCC patients with high mortality.

Patients and Methods: This multicenter cohort study included 746 EPCC (age $>65$ years) with a mean age of $72.00 \pm 5.24$ years, of whom $489(65.5 \%)$ were male. The cut-off value for the inflammation index was obtained using the optimal survival curve. The different inflammatory indicators were assessed using the concordance index (C-index), decision curve analysis (DCA), and prognostic receiver operating characteristic (ROC). The high mortality risk group of EPCC was defined by the 2011 Fearon Cancer Diagnostic Consensus. EPCC were divided into the high-risk group, which satisfies three diagnostic criteria, and a low-risk group, which satisfies only one or two diagnostic criteria.

Results: The C-index, DCA, and prognostic ROC indicated the superiority of advanced lung cancer inflammation index (ALI) compared with other indicators, including neutrophillymphocyte ratio (NLR), prognostic nutritional index (PNI), systemic immuneinflammation index (SII), and platelet-lymphocyte ratio (PLR). Whether ALI was used as a continuous or a categorical variable, ALI had a better prognostic value in EPCC compared with other inflammatory indicators. In particular, patients with low ALI $(<25.03)$ had a worse overall survival (OS) than patients with high ALI $(\geq 25.03)(P<0.001, \mathrm{HR}[95 \% \mathrm{CI}]=2.092$ [1.590-2.751]). The combination effect analysis showed that the risk of mortality of the patients in the low-ALI and high-risk groups was 3.095-fold higher than that of patients in the high-ALI and low-risk groups.

Conclusion: The prognostic and discriminative value of the inflammatory indicator ALI was better than that of NLR, PNI, SII, and PLR in EPCC. The high-risk group of EPCC with a low ALI would increase the death risk of OS.

Keywords: ALI, systemic inflammation, cancer cachexia, elderly, overall survival

\section{Introduction}

Cancer cachexia is a complex and debilitating disease resulting from cancer progression. It is estimated that approximately 2 million people worldwide die from cancer-related cachexia each year. ${ }^{1}$ Although cachexia may affect all cancer patients, it is most often associated with malignancies involving the gastrointestinal tract and lungs. ${ }^{2}$ Patients with pancreatic or gastric cancer suffer from the highest frequency of unintended weight loss, wherein patients can lose up to $30 \%$ of their 
pre-morbid body weight. ${ }^{2}$ The elderly are one of the most heterogeneous and vulnerable groups, and are at higher risk for nutritional problems and sarcopenia. Sarcopenia, also known as age-related muscle atrophy and weakness, can aggravate the defects associated with cancer cachexia in the elderly and complicate the conditions in this population. $^{3}$

Cancer cachexia is characterized by fat and skeletal muscle catabolism, leading to significant weight loss, decreased mobility and muscle function, fatigue, impaired quality of life, poor survival, and death in cases of a $25-$ $30 \%$ weight loss. ${ }^{4,5}$ Cancer cachexia results from a combination of reduced food intake, increased inflammation, and abnormal metabolism, including increased energy expenditure and excessive catabolism. ${ }^{6}$ Reduced food intake due to anorexia and physical inactivity promotes the degradation of muscle protein and induces fatigue. ${ }^{7}$ This vicious cycle may be exacerbated by an increase in inflammation, thereby further limiting quality of life and increasing mortality in patients. ${ }^{8}$

Systemic inflammation is considered a key mediator of cachexia. $^{9}$ The systemic inflammation in cachexia is caused by the interaction between the tumor and the peripheral tissue, and significantly participates in immune cell infiltration of the peripheral tissue and the tumor. ${ }^{10}$ Inflammation is usually associated with negative nitrogen balance and increased resting energy expenditure, leading to increased protein and energy requirements. ${ }^{11}$ Increasing evidence shows that the host inflammatory response is an important element in the occurrence and development of cancer, ${ }^{12}$ and is a main driving force behind changes in cancer metabolism. ${ }^{8}$ Indeed, systemic inflammation is a hallmark of cancer and is the main driving force for changes in cancer cachexia metabolism. ${ }^{13}$ The systemic inflammation of cancer is caused by a multitude of factors including cytokines and other inflammatory mediators released by tumors, cytokines and chemokines released by activated immune cells, ${ }^{14}$ and increased levels of circulating inflammatory components. These changes can be observed in the elderly as increased levels of tumor necrosis factor- $\alpha$ (TNF- $\alpha$ ), interleukin-6 (IL-6), IL-1 receptor antagonists, soluble TNF receptor, C-reactive protein (CRP), serum amyloid A, and neutrophil counts. ${ }^{15}$ Elderly have other conditions that favour weight loss and changes of body composition, in particular they typically present sarcopenia, that is independent from cancer, and can aggravate and further precipitate cachexia. ${ }^{15}$ For instance, IL-1 $\beta$ and TNF- $\alpha$ can act on glucose-sensitive neurons in the ventromedial nucleus (satisfaction area) and lateral hypothalamus (starvation area) to cause anorexia. ${ }^{16}$ The negative energy balance caused by anorexia leads to the aggravation of cancer cachexia. Decreased muscle mass and muscle strength are also common in the elderly. ${ }^{15}$ An inevitable result of aging, the continuous loss of skeletal muscle mass in patients with cancer cachexia causes further deterioration to the patient's function. An increase in the concentration of inflammatory markers, such as cytokines, is related to a decrease in lean muscle mass. ${ }^{15}$ Some cytokines, including TNF- $\alpha$, IL-6, IL-1 $\beta$, and INF-, reproduce cachexia symptoms in animal models. ${ }^{17}$ In a previous study, IL-6 was injected directly into the muscle of mice, and 14 days later, a $17 \%$ decrease in myofibrillar protein was observed, indicating a direct effect on the muscles. ${ }^{18}$ The combination of agerelated muscle loss and sustained muscle wasting caused by cancer cachexia may be a metabolic challenge that skeletal muscles in elderly patients cannot handle. The resulting metabolic abnormalities include increased glucose turnover, increased lipolysis, disarrayed hormone balance (such as in hypogonadism), increased insulin resistance, decreased net muscle protein balance, increased cytokine levels, and increased acute phase protein synthesis. ${ }^{19}$

At the time of writing, due to the increase in the aging population and the heterogeneity of the physical conditions of the elderly, simple and accurate prognostic indicators for elderly patients with cancer cachexia (EPCC) are urgently needed. Some currently available clinical prognostic indicators related to inflammation include advanced lung cancer inflammation index (ALI), neutrophil-lymphocyte ratio (NLR), prognostic nutritional index (PNI), systemic immune-inflammation index (SII), and platelet-lymphocyte ratio (PLR). However, the optimal prognostic inflammatory indicator in EPCC population still needs to be determined. This study aimed to identify the optimal inflammatory indicator for EPCC and to distinguish the EPCC population with high inflammation and high mortality risk.

\section{Materials and Methods}

\section{Patient Selection and Study Design}

This was a retrospective study of cancer data collected from multiple clinical centers in China from June 2012 to December 2019. Data included were strictly selected according to the inclusion and exclusion criteria. The 
inclusion criteria were age of 18 years and older, hospitalization time of 2 days or longer, diagnosis of cancer, and existence of signed consent form. The exclusion criteria were age of less than 18 years, hospitalization of less than 2 days, refusal to sign the consent form, and admitted to Intensive Care Unit at the beginning of recruitment. A total of 9727 patients with cancer were initially included in the cohort, and a total of 2560 patients were diagnosed with cancer cachexia. Finally, 746 EPCC (age $>65$ years) were included in this study. The details are presented in the flowchart (Figure S1).This retrospective study followed the Declaration of Helsinki. All participating units or institutions were approved by the ethics committee (registration number: ChiCTR1800020329), and all participants signed an informed consent form (Table S1).

\section{Patient Evaluation}

This study collected comprehensive patient information, including demographics, clinical parameters, anthropometric measurements, and laboratory tests. Age, sex, height, weight, and body mass index (BMI) of patients were obtained. In addition, tumor types (lung cancer, gastric cancer, colorectal cancer, esophageal cancer, hepatobiliary cancer, pancreatic cancer, breast cancer, uterine ovarian cancer, nasopharyngeal cancer, urological cancer, and other cancer subtypes), comorbidities (diabetes, hypertension, and coronary heart disease), daily habits (smoking, yes vs no; alcohol consumption, yes vs no; and tea consumption, yes vs no), tumor-node-metastasis (TNM) stage, radical resection, postoperative chemoradiotherapy, Eastern Cooperative Oncology Group Performance Status (ECOG PS), and Karnofsky Performance Status (KPS) were retrieved as clinical parameters. Clinical laboratory indicators (serum total protein, serum albumin, aspartate aminotransferase [AST], alanine transaminase [ALT], hemoglobin, white blood cells [WBC], lymphocytes, neutrophils, and platelets), nutrition-related information (weight loss, food intake, daily activity and function, and nutritional interventions), and 30-day mortality were also identified. BMI was calculated as follows: BMI $(\mathrm{kg} / \mathrm{m} 2)=$ weight $/$ height $^{2}$. The BMI classification was based on Chinese classification standards. Systemic inflammation indices were obtained according to the following formulas: NLR $=$ neutrophil $($ count $/ \mathrm{mm} 3) /$ lymphocyte $($ count $/ \mathrm{mm} 3) ;{ }^{20}$ ALI $=$ BMI $(\mathrm{kg} / \mathrm{m} 2) \times$ albumin $(\mathrm{g} / \mathrm{dl}) / \mathrm{NLR} ;{ }^{21} \mathrm{PNI}=10 \times$ albumin $(\mathrm{g} / \mathrm{dl})+0.005 \times$ lymphocyte $($ count $/ \mathrm{mm} 3) ;{ }^{22} \mathrm{SII}=$ platelet (count $/ \mathrm{mm} 3) \times$ neutrophil (count $/ \mathrm{mm} 3) /$ lymphocyte (count/ $\mathrm{mm} 3){ }^{20} \mathrm{PLR}=$ platelet $($ count $/ \mathrm{mm} 3) /$ lymphocyte $(\mathrm{count} /$ mm3). ${ }^{20}$ The best survival cutoffs for different inflammatory indicators were obtained using $\mathrm{R}$ software: ALI (25.03), NLR (3.47), PNI (42.40), SII (819.71), and PLR (129.80) (Figure S2). ${ }^{23}$ Patient-generated subjective global assessment (PGSGA) criteria were obtained through patient's self-assessment and professional assessment. The PGSGA was divided into three groups according to the scores: well-nourished group (0-3), moderately malnourished group, ${ }^{4-8}$ and severely malnourished group $(\geq 9) .{ }^{24}$

\section{Assessment of Cancer Cachexia}

The diagnostic criteria for cancer cachexia in this study adopted the 2011 Fearon Cancer Diagnostic Consensus, ${ }^{4}$ which utilizes the following criteria: 1) weight loss greater than $5 \%$ of starting body weight in the past 6 months, unconsciousness and 2) BMI less than $20 \mathrm{~kg} / \mathrm{m} 2$ (or sarcopenia) and any degree of weight loss greater than $2 \%$. Skeletal muscle depletion was estimated by the mid upperarm muscle area (men: $<32 \mathrm{~cm}^{2}$, women: $<18 \mathrm{~cm}^{2}$ ).

We performed a survival curve analysis for the three different diagnostic conditions for cancer cachexia: 1) weight loss greater than $5 \%$, 2) BMI less than $20 \mathrm{~kg} / \mathrm{m}^{2}$ and weight loss greater than $2 \%$, and 3) sarcopenia and weight loss greater than $2 \%$. The OS of EPCC who satisfied all three diagnostic criteria at the same time was significantly worse than those who satisfied only one or two criteria $(P<0.001)$. However, there was no difference in OS between patients who satisfied one and those who satisfied two diagnostic criteria $(P>0.05)$ (Figure S3). Therefore, we divided EPCC into the high-risk group (satisfying three diagnostic criteria at the same time) and low-risk group (satisfying only one or two diagnostic criteria) (Figure 1A).

\section{Outcome Evaluation}

The follow-up records of all patients were obtained in strict accordance with the established content from telephone consultation or follow-up in the outpatient clinic. The observed outcome was the overall survival (OS) of the patient, that is, from the time of the first diagnosis of cancer to the time of death, the time of withdrawal from the study, or the time of the last follow-up.

\section{Statistical Analysis}

In this study, continuous variables in the baseline data were calculated as mean \pm standard deviation (SD) or median (interquartile range, IQR: quartile 1 to quartile 3), while categorical variables were calculated as absolute 

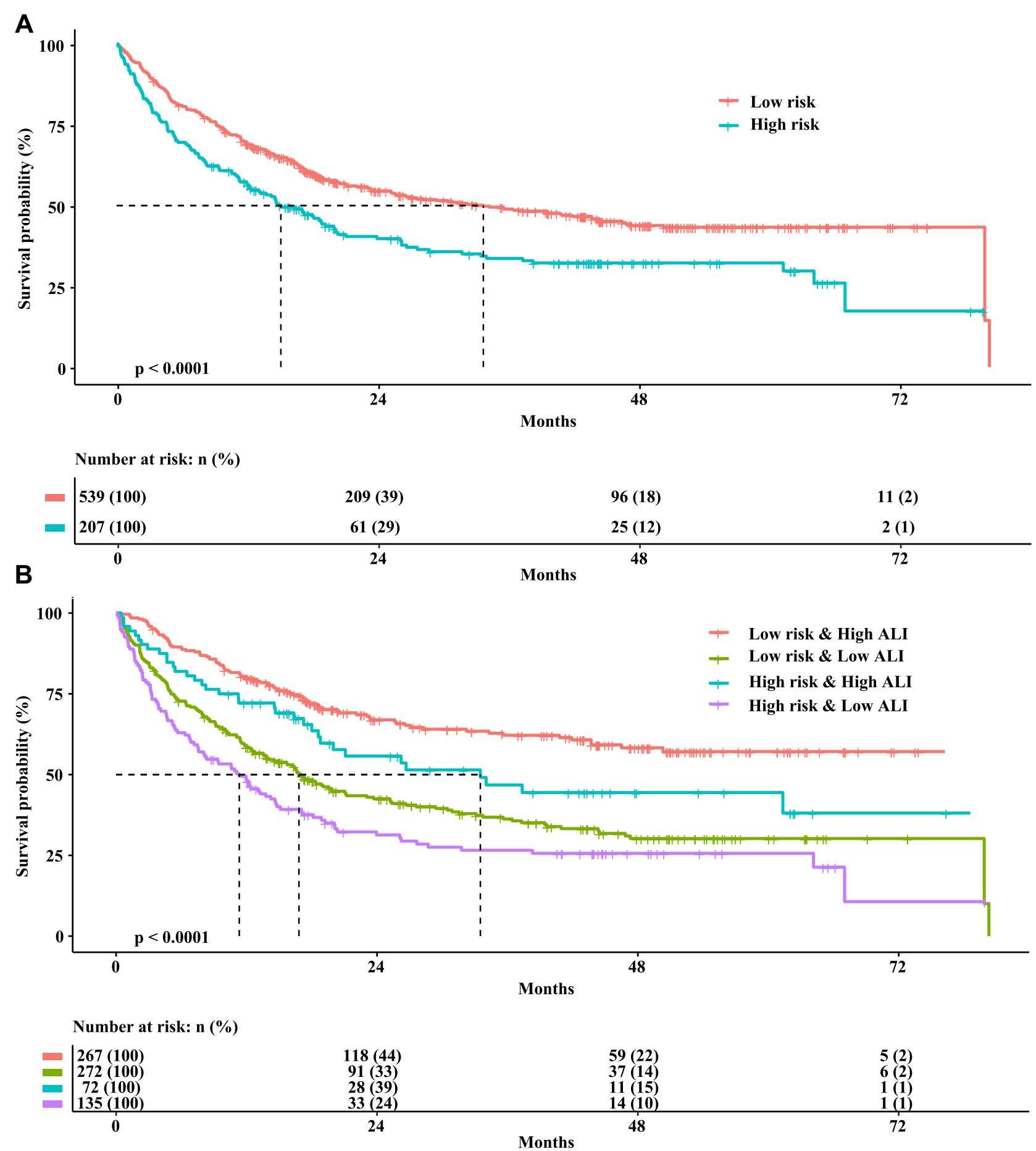

Figure I The Kaplan-Meier survival curves of OS in EPCC. (A) The survival curve of different risk groups based on diagnostic criterion of Fearon cancer cachexia; (B) combined effect survival curve.

Abbreviations: ALI, advanced lung cancer inflammation index; OS, overall survival; EPCC, elderly patients with cancer cachexia.

numbers or proportions. The independent Student's $t$-test for continuous variables or the $\chi^{2}$ test for categorical data were used for comparison between the two groups. The Kaplan-Meier method was used to estimate survival curves. Hazard ratios (HRs) and their 95\% confidence intervals (CIs) were calculated to assess the mortality risk and reliability of values. In the multivariate Cox regression model for risk of mortality, model 0 was an unadjusted model, model 1 was adjusted for age, sex, and TNM staging, and model 2 was adjusted for all 
variables. All statistical analyses were performed through the $\mathrm{R}$ platform. Two-sided $P$-values $<0.05$ were considered statistically significant.

\section{Results}

\section{Baseline Characteristics}

In this study, the average age of the 746 EPCC was 72.00 \pm 5.24 years, of which $489(65.50 \%)$ were male, and the average survival time was 25.4 months. Additionally, a total of 343 deaths were observed during the study period and the median survival time was 44.3 months. Based on the diagnostic criteria for cancer cachexia, there were $655(87.80 \%)$ elderly patients with a weight loss greater than $5 \%, 371(49.70 \%)$ elderly patients with a BMI of less than $20 \mathrm{~kg} / \mathrm{m} 2$ and a weight loss greater than $2 \%$, and $319(42.80 \%)$ elderly patients with sarcopenia and a weight loss greater than $2 \%$ (Table 1 ). We also observed the overall mortality rate of EPCC from 1 to 5 years: at 12 months, $34.3 \%$ (95\% CI: $62.3-69.2 \%)$; at 24 months, $49.5 \%$ (95\% CI: $46.8-54.4 \%)$; at 36 months, $55.3 \%$ (95\% CI: $40.9-48.7 \%)$; at 48 months, $59.4 \%$ (95\% CI: 36.8-44.9\%); and at 60 months, $59.8 \%$ (95\% CI: 36.4 $44.5 \%$ ), which resulted in a rate of 278 events per 1000 patient-years.

\section{Comparison of Inflammatory Indicators}

We compared the prognostic predictive and discriminative ability of different inflammatory indicators (ALI, NLR, PNI, SII, and PLR) in EPCC. The concordance index (C-index) and $95 \%$ CIs of different indicators was as follows: $\mathrm{ALI}=0.634(0.604-0.664), \mathrm{NLR}=0.624$ (0.594-0.654), PNI $=0.595(0.563-0.626)$, SII $=0.594$ (0.564-0.624), and PLR $=0.541 \quad(0.510-0.573)$. Additionally, a decision curve analysis (DCA) was performed to assess the discriminative ability and clinical utility of the prognostic markers, and the results showed that ALI was superior to other inflammatory indicators (Figure 2A).

For the prognostic predictive ability of different inflammatory indicators in EPCC, we conducted a prognostic receiver operating characteristic (ROC) curve analysis, and the results showed that the area under the curve (AUC) of ALI was greater than that of other indicators (Figure 2B). The survival curve results showed that the prognosis of patients with low ALI $(<25.03)$ and low PNI $(<42.40)$ were worse than that of patients with high ALI $(\geq 25.03)$ and high PNI $(\geq 42.40)$, respectively,
Table I Demographic and Clinical Characteristics

\begin{tabular}{|c|c|}
\hline \multirow[t]{2}{*}{ Characteristics } & Overall Patients \\
\hline & $(n=746)$ \\
\hline Age, years, (mean (SD)) & $72.00(5.24)$ \\
\hline \multicolumn{2}{|l|}{ Sex, n (\%) } \\
\hline Male & $489(65.50)$ \\
\hline Female & $257(34.50)$ \\
\hline \multicolumn{2}{|l|}{ Sites of cancer, n (\%) } \\
\hline Lung cancer, n (\%) & $164(22.00)$ \\
\hline Gastric cancer, n (\%) & $170(22.80)$ \\
\hline Colorectal cancer, n (\%) & $199(26.70)$ \\
\hline Esophageal cancer, n (\%) & $90(12.10)$ \\
\hline Hepatobiliary cancer, n (\%) & $32(4.30)$ \\
\hline Pancreatic cancer, n (\%) & $19(2.50)$ \\
\hline Breast cancer, n (\%) & $22(2.90)$ \\
\hline Utero ovarian cancer, n (\%) & $21(2.80)$ \\
\hline Nasopharyngeal cancer, n (\%) & $13(1.70)$ \\
\hline Urological cancer, n (\%) & II (I.50) \\
\hline Other cancer subtypes, n (\%) & $5(0.70)$ \\
\hline Diabetes, yes, n (\%) & $98(13.10)$ \\
\hline Hypertension, yes, n (\%) & $192(25.70)$ \\
\hline Coronary heart disease, yes, n (\%) & $70(9.40)$ \\
\hline Family history of cancer, yes, $n$ (\%) & $94(12.60)$ \\
\hline Smoking, yes, n (\%) & $370(49.60)$ \\
\hline Alcohol consumption, yes, $\mathrm{n}$ (\%) & $160(21.40)$ \\
\hline Tea consumption, $\mathrm{n}(\%)$ & $198(26.50)$ \\
\hline BMI, kg/m^2 (mean (SD)) & $20.41(3.17)$ \\
\hline \multicolumn{2}{|l|}{ TNM stage, n (\%) } \\
\hline I & $50(6.70)$ \\
\hline II & $159(21.30)$ \\
\hline III & $200(26.80)$ \\
\hline IV & $337(45.20)$ \\
\hline Radical resection, yes, n (\%) & $215(28.80)$ \\
\hline Postoperative chemoradiotherapy, yes, n (\%) & $325(43.60)$ \\
\hline \multicolumn{2}{|l|}{ ECOG PS, n (\%) } \\
\hline$\leq 2$ & $598(80.16)$ \\
\hline$>2$ & $148(19.84)$ \\
\hline KPS (mean (SD)) & $79.26(17.76)$ \\
\hline Serum total protein $(g / L)$ (mean $(S D))$ & $65.01(8.07)$ \\
\hline Serum albumin $(g / L)$ (mean $(S D))$ & $35.83(5.55)$ \\
\hline AST (U/L) (median (IQR)) & $21.00(16.73,29.80)$ \\
\hline ALT (U/L) (median (IQR)) & $17.00(11.00,27.70)$ \\
\hline Hemoglobin (g/L) (mean (SD)) & II $4.49(21.22)$ \\
\hline WBC $\left(\times 10^{\wedge} 9 / L\right)($ mean $(S D))$ & $7.29(3.96)$ \\
\hline Neutrophils (×10^9/L) (mean (SD)) & $5.02(3.26)$ \\
\hline Lymphocytes (×10^9/L) (mean (SD)) & $\mathrm{I} .42(0.95)$ \\
\hline Platelet $\left(\times 10^{\wedge} 9 / \mathrm{L}\right)($ mean $(\mathrm{SD}))$ & $224.58(95.23)$ \\
\hline 30-day mortality, yes, n (\%) & $24(3.20)$ \\
\hline \multicolumn{2}{|l|}{ PGSGA, n (\%) } \\
\hline Well nourished $(0-3)$ & $103(13.80)$ \\
\hline
\end{tabular}

(Continued) 
Table I (Continued).

\begin{tabular}{|c|c|}
\hline \multirow[t]{2}{*}{ Characteristics } & Overall Patients \\
\hline & $(n=746)$ \\
\hline Moderately malnourished (4-8) & $40 I(53.80)$ \\
\hline Severely malnourished (>9) & $242(32.40)$ \\
\hline Nutritional intervention, yes, $\mathrm{n}(\%)$ & $174(23.30)$ \\
\hline Diagnostic criteria for cancer cachexia & \\
\hline Weight loss $>5 \%$, yes, $n(\%)$ & $655(87.80)$ \\
\hline $\begin{array}{l}\mathrm{BMI}<20 \mathrm{~kg} / \mathrm{m}^{2} \text { and weight loss }>2 \% \text {, yes, } \\
\mathrm{n}(\%)\end{array}$ & $371(49.70)$ \\
\hline Sarcopenia and weight loss $>2 \%$, yes, $n(\%)$ & $319(42.80)$ \\
\hline ALI, (median (IQR)) & $22.28(11.90,38.04)$ \\
\hline NLR, (median (IQR)) & $3.33(1.95,5.60)$ \\
\hline PNI, (median (IQR)) & $43.12(38.31,47.10)$ \\
\hline SII, (median (IQR)) & $\begin{array}{c}712.92(373.04 \\
1244.75)\end{array}$ \\
\hline PLR, (median (IQR)) & $\begin{array}{c}165.23(113.52 \\
241.63)\end{array}$ \\
\hline
\end{tabular}

Abbreviations: SD, standard deviation; IQR, interquartile range; BMI, body mass index; ECOG PS, Eastern Cooperative Oncology Group Performance Status; KPS, Karnofsky Performance Status; AST, aspartate aminotransferase; ALT, alanine transaminase; WBC, white blood cells; ALI, advanced lung cancer inflammation index; NLR, neutrophil-lymphocyte ratio; PNI, prognostic nutritional index; SII, systemic immune-inflammation index; PLR, platelet-lymphocyte ratio; PGSGA, PatientGenerated Subjective Global Assessment.

while patients with high NLR ( $\geq 3.47)$, high SII ( $\geq 819.71)$, and high PLR $(\geq 129.80)$ had a worse prognosis than those with low NLR $(<3.47)$, low SII $(<819.71)$, and low PLR $(<129.80)$, respectively (Figure S4).

Multivariate Cox regression survival analysis found that compared with other inflammation indices, ALI showed a good prognostic predictive ability in EPCC as a continuous variable or a categorical variable (Table 2, Figure S5). When ALI was used as a continuous variable, the risk of mortality in EPCC decreased with an increase in ALI (model 2: adjusted $P<0.001, \mathrm{HR}[95 \% \mathrm{CI}]=0.743$ [0.623-0.885]). When ALI was used as a binary variable, compared with patients in the high-ALI $(\geq 25.03)$ group, patients with low ALI $(<25.03)$ had an increased risk of mortality (model 2: adjusted $P<0.001$, HR $[95 \% \mathrm{CI}]=$ $2.092[1.590-2.751])$. When ALI was treated as a quartile variable, compared with patients in the first quartile (ALI>38.04) group, the risk of mortality in EPCC in the third and fourth quartile groups was significantly increased (model 2: $P<0.001$; quartile 3 , adjusted $P<0.001$, HR [95\% CI] $=2.108$ [1.477-3.007]); quartile 4, adjusted $P<0.001$, HR [95\% CI] $=2.296$ [1.476-3.570]).

However, we also excluded patients who died within 6 months and performed a sensitivity analysis. The results showed that compared with other inflammatory indicators, ALI showed a good prognostic ability whether it was a continuous variable or a categorical variable. These results are similar to those of previous multivariate survival analyses (Table S2).

\section{Analysis of the Distribution, Correlation, and Prognosis of ALI}

Based on the ALI cut-off value, patients were divided into high- $(\geq 25.03, \mathrm{n}=339)$ and low-ALI groups $(<25.03$, $\mathrm{n}=407$ ). Comparison of baseline clinical characteristics between the two groups showed that age, tumor type, BMI, TNM stage, KPS, serum total protein, serum albumin, hemoglobin, WBC, lymphocytes, neutrophils, platelets, 30-day mortality, and PGSGA were significantly different (all $P<0.05$ ) ( Table S3).

In the EPCC cohort, we investigated the distribution of ALI in different TNM stages and cancer types based on different age and sex subgroups. The results showed that there was a significant difference in the distribution of patients with gastric cancer $(P<0.05)$ (Figure 3).

Pearson correlation analysis showed that ALI was significantly correlated with serum albumin $(\mathrm{R}=0.40)$, neutrophils $(\mathrm{R}=-0.48)$, and lymphocytes $(\mathrm{R}=0.41) \quad$ (all $P<0.05)$. Correlation analyses of different sex subgroups and age subgroups showed consistent significant correlation results $(\mathrm{R}>0.3$ or $\mathrm{R}<-0.3, P<0.05)$ (Figure $\mathrm{S} 6)$.

To compare the prognostic accuracy of ALI in EPCC, the calibration curves showed that ALI showed good consistency for 1-, 3-, and 5-year prognosis predictions. The risk model we constructed further showed that the lower the ALI score, the higher the risk of mortality, and the worse the prognosis in EPCC (Figure S7).

\section{Combined Risk Effect Analysis}

Compared with patients in the low-risk group, the risk of mortality in the high-risk group was significantly increased (model 2: adjusted $P=0.017$, HR [95\% CI] $=1.400$ [1.078-1.819]) (Table 3). We performed a combined-effect analysis of the high- and low-ALI groups and the high- and low-risk groups. The results showed that the mortality risk of patients in the low-ALI and high-risk groups reached 3.095-fold compared with patients in the high-ALI and low-risk groups, respectively (adjusted $P<0.001,95 \%$ CI $=2.085-4.592$ ) (Table 3, Figure 1B). 

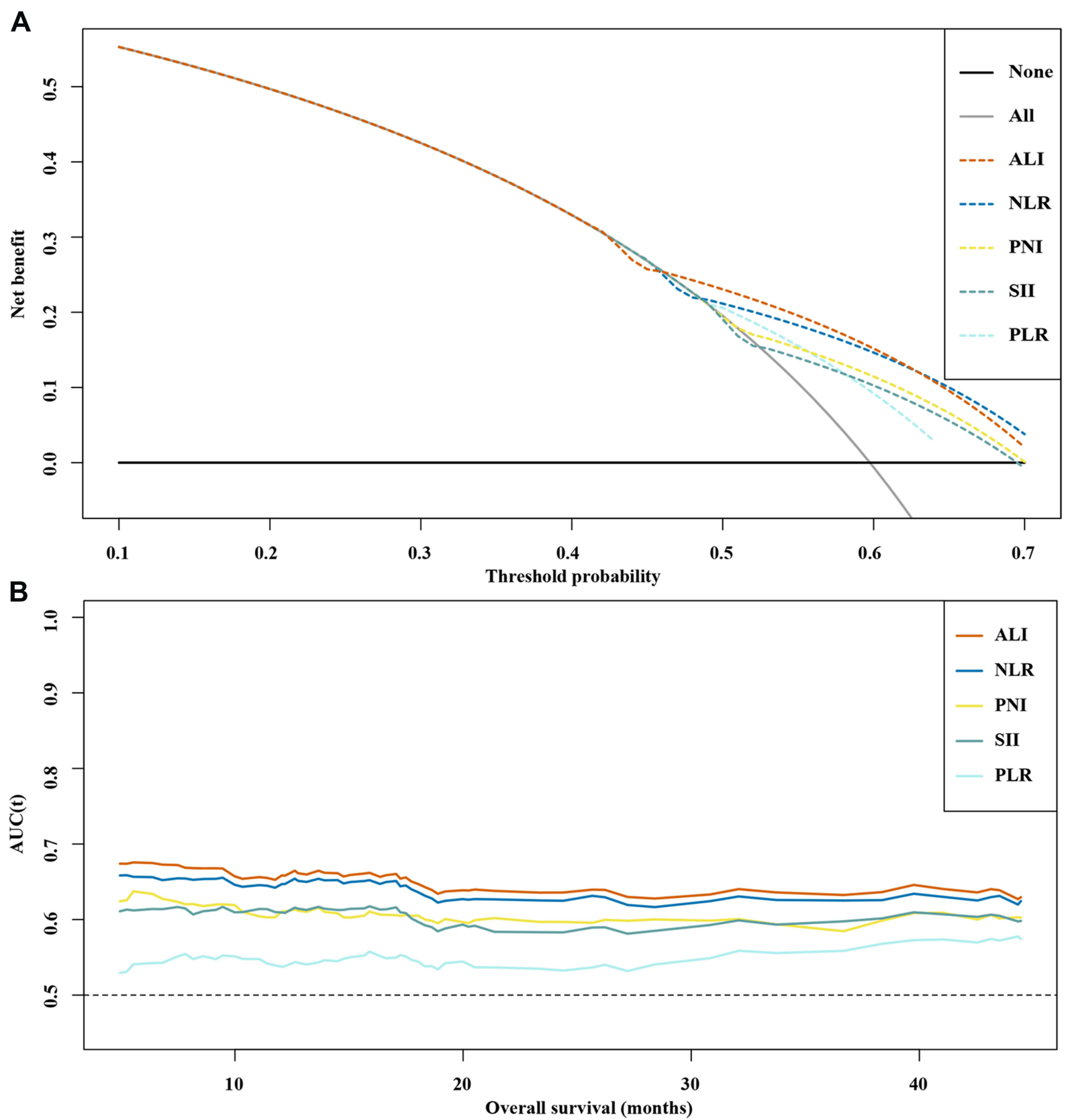

Figure $2 \mathrm{DCA}$ and prognostic ROC curves of different inflammation markers.(A) DCA; (B) ROC.

Abbreviations: ALI, advanced lung cancer inflammation index; NLR, neutrophil-lymphocyte ratio; PNI, prognostic nutritional index; SII, systemic immune-inflammation index; PLR, platelet-lymphocyte ratio; ROC, receiver operating characteristic curve; DCA, decision curve analysis.

\section{Stratified Analysis}

The stratified analysis showed a significant interaction between ALI (high ALI, $\geq 25.03$ vs low ALI, <25.03) and the EPCC mortality risk in BMI $(\mathrm{kg} / \mathrm{m} 2 ;<18.5$, 18.5-23.9, and $>23.9 ; \quad P$ for interaction $<0.001$ ). However, no significant interaction was observed in the other subgroup parameters $(P$ for interaction $>0.05)$ (Figure 4).

\section{Discussion}

Our understanding of cancer progression has evolved from emphasizing the internal changes in cancer cells to emphasizing the key interactions between cancer and noncancerous cells in the primary tumor microenvironment. ${ }^{25}$ In fact, non-tumor cells in the tumor microenvironment, including immune cells, fibroblasts, and endothelial cells, play an important role in regulating the secretion of cachexia- 
Table 2 Univariate and Multivariate Analysis of the OS in EPCC

\begin{tabular}{|c|c|c|c|c|c|c|}
\hline \multirow[t]{2}{*}{ Variables } & \multicolumn{2}{|c|}{ OS (Model 0) ${ }^{a}$} & \multicolumn{2}{|c|}{ OS (Model I) } & \multicolumn{2}{|c|}{ OS (Model 2) } \\
\hline & $\begin{array}{l}\text { Crude HR (95\% } \\
\text { CI) }\end{array}$ & $\begin{array}{c}\text { Crude } \\
P\end{array}$ & $\begin{array}{l}\text { Adjusted HR (95\% } \\
\mathrm{Cl)}\end{array}$ & $\begin{array}{c}\text { Adjusted } \\
\qquad\end{array}$ & $\begin{array}{l}\text { Adjusted HR (95\% } \\
\mathrm{CI)}\end{array}$ & $\begin{array}{c}\text { Adjusted } \\
P\end{array}$ \\
\hline $\begin{array}{l}\text { ALI } \\
\text { As continuous (per } \\
\text { SD) }\end{array}$ & $0.614(0.525-0.719)$ & $<0.001$ & $0.640(0.550-0.752)$ & $<0.001$ & $0.743(0.623-0.885)$ & $<0.001$ \\
\hline $\begin{array}{l}\text { By cut-off } \\
A L I \geq 25.03 \\
A L I<25.03\end{array}$ & $\begin{array}{l}\text { I } \\
2.231(1.810-2.750)\end{array}$ & $<0.001$ & $\begin{array}{l}\text { I } \\
2.263(1.832-2.796)\end{array}$ & $<0.001$ & $\begin{array}{l}\text { I } \\
2.092(1.590-2.75 I)\end{array}$ & $<0.001$ \\
\hline $\begin{array}{l}\text { By Interquartile } \\
\text { Q1 (38.04 ) } \\
\text { Q2 (22.28 38.04) } \\
\text { Q3 (II.90 22.28) } \\
\text { Q4 ( } 11.90) \\
\text { P for trend }\end{array}$ & $\begin{array}{l}\text { I } \\
1.559(1.130-2.152) \\
2.369(1.745-3.217) \\
2.902(2.146-3.924)\end{array}$ & $\begin{array}{l}0.007 \\
<0.001 \\
<0.001 \\
<0.001\end{array}$ & $\begin{array}{l}\text { I } \\
1.317(0.953-1.819) \\
2.150(1.58 I-2.925) \\
2.770(2.044-3.754)\end{array}$ & $\begin{array}{l}0.095 \\
<0.001 \\
<0.001 \\
<0.001\end{array}$ & $\begin{array}{l}\text { I } \\
1.264(0.900-1.773) \\
2.108(1.477-3.007) \\
2.296(1.476-3.570)\end{array}$ & $\begin{array}{l}0.176 \\
<0.001 \\
<0.001 \\
<0.001\end{array}$ \\
\hline $\begin{array}{l}\text { NLR } \\
\text { As continuous (per } \\
\text { SD) }\end{array}$ & $1.238(1.131-1.356)$ & $<0.001$ & 1.221 (1.114-1.337) & $<0.001$ & $1.921(1.484-2.486)$ & $<0.001$ \\
\hline $\begin{array}{l}\text { By cut-off } \\
N L R<3.47 \\
N L R \geq 3.47\end{array}$ & $\begin{array}{l}\text { I } \\
2.142(1.754-2.616)\end{array}$ & $<0.001$ & $2.131(1.743-2.607)$ & $<0.001$ & $\begin{array}{l}\text { I } \\
1.916(1.48 I-2.480)\end{array}$ & $<0.001$ \\
\hline $\begin{array}{l}\text { By Interquartile } \\
\text { Q1 ( I.95) } \\
\text { Q2 (1.95 3.33) } \\
\text { Q3 (3.33 5.60) } \\
\text { Q4 (5.60 ) } \\
\text { P for trend }\end{array}$ & $\begin{array}{l}\text { I } \\
1.380(1.000-1.906) \\
2.242(1.660-3.027) \\
2.724(2.025-3.664)\end{array}$ & $\begin{array}{l}0.050 \\
<0.001 \\
<0.001 \\
<0.001\end{array}$ & $\begin{array}{l}\text { I } \\
I .136(0.82 I-1.570) \\
I .979(I .46 I-2.679) \\
2.5 I 5(I .866-3.39 I)\end{array}$ & $\begin{array}{l}0.442 \\
<0.001 \\
<0.001 \\
<0.001\end{array}$ & $\begin{array}{l}\text { I } \\
1.066(0.761-1.494) \\
1.924(1.367-2.707) \\
1.926(1.276-2.908)\end{array}$ & $\begin{array}{c}0.710 \\
<0.001 \\
0.002 \\
<0.001\end{array}$ \\
\hline $\begin{array}{l}\text { PNI } \\
\text { As continuous (per } \\
\text { SD) }\end{array}$ & $0.776(0.702-0.857)$ & $<0.001$ & $0.764(0.690-0.846)$ & $<0.001$ & $0.849(0.707-1.020)$ & 0.081 \\
\hline $\begin{array}{l}\text { By cut-off } \\
\mathrm{PNI} \geq 42.40 \\
\mathrm{PNI}<42.40\end{array}$ & $\begin{array}{l}\mathrm{I} \\
\mathrm{I} .780(\mathrm{I} .46 \mathrm{I}-2.167)\end{array}$ & $<0.001$ & I.812 (1.483-2.214) & $<0.001$ & I.896 (1.340-2.68I) & $<0.001$ \\
\hline $\begin{array}{l}\text { By Interquartile } \\
\text { QI (47.10 ) } \\
\text { Q2 (43.13 47.10) } \\
\text { Q3 (38.3I 43.13) } \\
\text { Q4 ( 38.3I) } \\
\text { P for trend }\end{array}$ & $\begin{array}{l}\text { I } \\
1.374(1.009-1.870) \\
1.868(1.389-2.514) \\
2.220(1.657-2.974)\end{array}$ & $\begin{array}{l}0.044 \\
<0.001 \\
<0.001 \\
<0.001\end{array}$ & $\begin{array}{l}\text { I } \\
1.376(1.010-1.874) \\
2.021(1.499-2.723) \\
2.236(1.663-3.008)\end{array}$ & $\begin{array}{l}0.043 \\
<0.001 \\
<0.001 \\
<0.001\end{array}$ & $\begin{array}{l}\text { I } \\
1.290(0.928-1.794) \\
2.018(1.365-2.983) \\
1.976(1.175-3.323)\end{array}$ & $\begin{array}{c}0.129 \\
<0.001 \\
0.010 \\
0.003\end{array}$ \\
\hline $\begin{array}{l}\text { SII } \\
\text { As continuous (per } \\
\text { SD) }\end{array}$ & $1.205(1.112-1.306)$ & $<0.001$ & 1.159 (1.068-1.258) & $<0.001$ & $1.026(0.907-1.605)$ & 0.685 \\
\hline $\begin{array}{l}\text { By cut-off } \\
\text { SII <8I9.7I } \\
\text { SII } \geq 8|9.7|\end{array}$ & I.726(1.4I8-2.100) & $<0.001$ & $\begin{array}{l}\text { I } \\
1.573(1.290-1.918)\end{array}$ & $<0.001$ & $\begin{array}{l}\text { I } \\
\text { I.255 (0.979-I.608) }\end{array}$ & 0.073 \\
\hline
\end{tabular}

(Continued) 
Table 2 (Continued).

\begin{tabular}{|c|c|c|c|c|c|c|}
\hline \multirow[t]{2}{*}{ Variables } & \multicolumn{2}{|c|}{ OS (Model 0) ${ }^{a}$} & \multicolumn{2}{|c|}{ OS (Model I) } & \multicolumn{2}{|c|}{ OS (Model 2) } \\
\hline & $\begin{array}{l}\text { Crude HR (95\% } \\
\text { CI) }\end{array}$ & $\begin{array}{c}\text { Crude } \\
P\end{array}$ & $\begin{array}{l}\text { Adjusted HR (95\% } \\
\text { Cl) }\end{array}$ & $\begin{array}{c}\text { Adjusted } \\
P\end{array}$ & $\begin{array}{l}\text { Adjusted HR (95\% } \\
\mathrm{Cl})\end{array}$ & $\begin{array}{c}\text { Adjusted } \\
P\end{array}$ \\
\hline \multicolumn{7}{|l|}{ By Interquartile } \\
\hline QI ( 373.04) & 1 & & I & & I & \\
\hline Q2 (373.04 7| 2.92) & 1.491 (1.093-2.033) & 0.012 & $1.430(1.048-1.950)$ & 0.024 & $1.425(1.013-2.006)$ & 0.042 \\
\hline Q3 (7I2.92 1244.75) & I.857 (1.375-2.508) & $<0.001$ & $1.636(1.209-2.212)$ & 0.001 & $1.525(1.085-2.145)$ & 0.015 \\
\hline Q4 (I244.75 ) & $2.254(1.680-3.023)$ & $<0.001$ & $2.090(1.556-2.806)$ & $<0.001$ & $1.569(I .033-2.38 I)$ & 0.034 \\
\hline$P$ for trend & & $<0.001$ & & $<0.001$ & & 0.031 \\
\hline \multicolumn{7}{|l|}{ PLR } \\
\hline $\begin{array}{l}\text { As continuous (per } \\
\text { SD) }\end{array}$ & $0.722(0.446-|| 70)$. & 0.186 & $0.799(0.48 I-I .327)$ & 0.410 & $0.802(0.46 \mathrm{I}-\mathrm{I} .397)$ & 0.435 \\
\hline \multicolumn{7}{|l|}{ By cut-off } \\
\hline PLR $<129.80$ & I & & I & & I & \\
\hline$P L R \geq 129.80$ & $1.484(1.191-1.849)$ & $<0.001$ & $1.365(1.093-1.703)$ & 0.006 & I.25। (0.940-I.665) & 0.125 \\
\hline \multicolumn{7}{|l|}{ By Interquartile } \\
\hline QI ( 1 I3.52) & 1 & & I & & I & \\
\hline Q2 (I I3.52 I65.23) & 1.343 (1.004-1.797) & 0.047 & $1.248(0.932-|.67|)$ & 0.138 & I.I68 (0.850-I.603) & 0.338 \\
\hline Q3 (I65.23 24I.63) & $1.299(0.969-1.740)$ & 0.080 & I.16I (0.864-I.56I) & 0.323 & $0.939(0.654-1.347)$ & 0.732 \\
\hline Q4 (24I.63 ) & $1.572(1.183-2.088)$ & 0.002 & 1.508 (I.I34-2.007) & 0.005 & I.I88 (0.807-I.749) & 0.382 \\
\hline$P$ for trend & & 0.004 & & 0.011 & & 0.607 \\
\hline
\end{tabular}

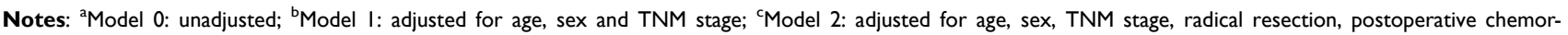
adiotherapy, ECOG PS, KPS, BMI, family history of cancer, tea consumption, alcohol consumption, smoking, diabetes, hypertension, coronary heart disease, AST, ALT, hemoglobin, serum total protein, serum albumin, WBC, lymphocytes, neutrophils, platelet, 30-day mortality, PGSGA, nutritional intervention.

Abbreviations: SD, standard deviation; OS, overall survival; HR, hazards ratio; CI, confidence interval; BMI, body mass index; ECOG PS, Eastern Cooperative Oncology Group Performance Status; KPS, Karnofsky Performance Status; AST, aspartate aminotransferase; ALT, alanine transaminase; WBC, white blood cells; ALI, advanced lung cancer inflammation index; NLR, neutrophil-lymphocyte ratio; PNI, prognostic nutritional index; SIl, systemic immune-inflammation index; PLR, platelet-lymphocyte ratio; PGSGA, Patient-Generated Subjective Global Assessment.

inducing factors from tumors. ${ }^{10}$ In the resistance phase, immune cells (such as macrophages, dendritic cells, T cells, and $\mathrm{B}$ cells) are activated and accompanied by the release of pro-inflammatory factors (IL-6, IL-1, TNF- $\alpha$ ), hypoxiainducible factor-1, and reactive oxygen species(ROS), which determine the specific changes in energy metabolism. In the absence of specific immunity, patients often have general non-specific immune responses mediated by macrophages (such as cytokine storm), and the body's continuous inflammatory response further leads to the phenomena of tolerance and the symptoms of cancer cachexia (such as anorexia and muscle wasting). ${ }^{26}$

Elderly might be inflamed as consequence of inflammaging. One of the main features of aging is the increase in pro-inflammatory mediators in the blood, and the parallel reduction in the ability to produce effective inflammatory responses to sufficient immunogenic stimulations. ${ }^{27}$ In this study, the optimal inflammation index was investigated in EPCC. Both the distinguishing ability and prognostic value of ALI were superior to those of NLR, PNI, SII, and PLR. For the prognostic prediction of EPCC, the ALI showed consistent discrimination. Notably, ALI had a good prognostic value, whether as a continuous or a categorical variable. For every SD increase in ALI, the patient's risk of mortality decreased by 0.733 -fold. The prognosis of EPCC with low ALI (< 25.03) was worse than those with high ALI $(\geq 25.03)$. Thus, ALI could be used as an independent prognostic factor in EPCC.

In recent years, a growing number of studies have suggested that ALI, a new inflammation index, can be used to assess the survival of patients with a variety of malignant tumors. ALI was originally used to assess the prognosis of lung cancer patients, such as non-small cell lung cancer $^{28}$ and small cell lung cancer. ${ }^{29}$ Soon after, researchers found that ALI is also a good independent prognostic indicator in nasopharyngeal carcinoma, ${ }^{30}$ head and neck squamous cell carcinoma, ${ }^{31}$ thymic epithelial 
A

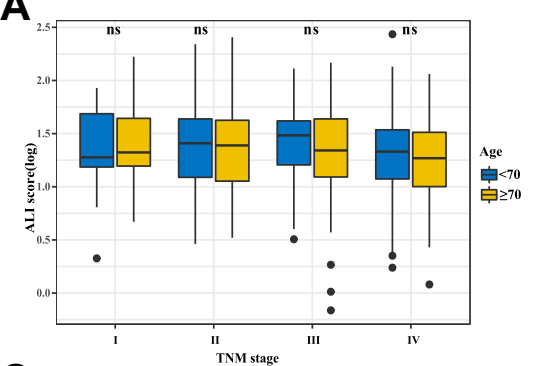

C

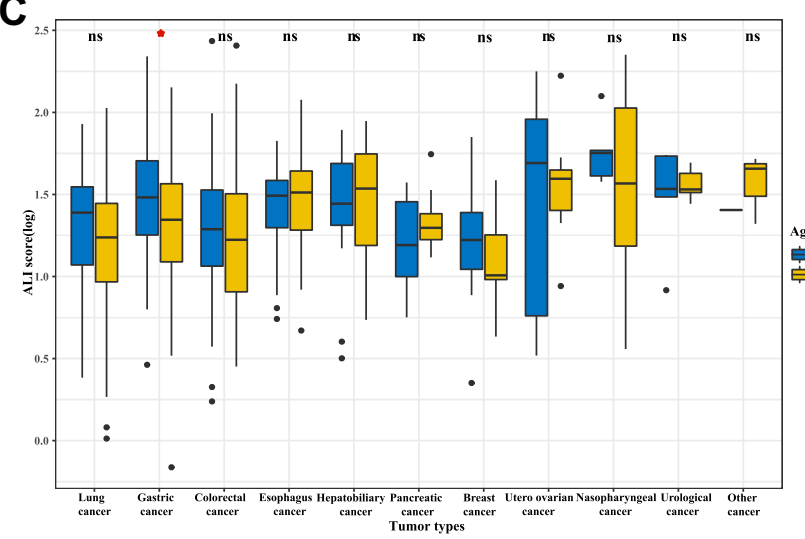

B
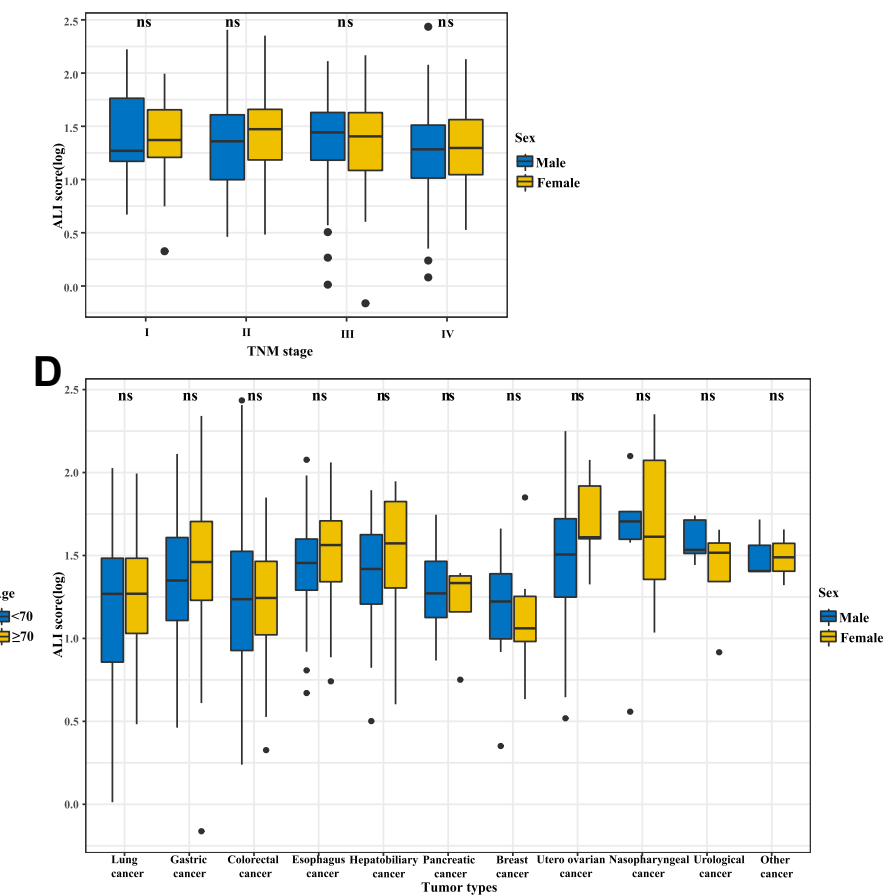

Figure 3 The distribution of ALI in EPCC between age subgroups and sex subgroups. (A) TNM stage stratified by age; (B) TNM stage stratified by sex; (C) tumor types stratified by age; (D) tumor types stratified by sex. $* P<0.05$.

Abbreviations: ALI, advanced lung cancer inflammation index; EPCC, elderly patients with cancer cachexia; TNM stage, tumor-node-metastasis stage; ns, not significant.

tumors, ${ }^{32}$ esophageal cancer, ${ }^{32}$ gastric cancer, ${ }^{21,33}$ colorectal cancer, ${ }^{34,35}$ melanoma, ${ }^{36}$ and diffuse large B-cell lymphoma. ${ }^{37} \mathrm{ALI}$ is an index related to inflammation and nutritional status. ${ }^{21}$ The difference between ALI and other previously reported indicators is that ALI not only includes inflammation related NLR and albumin, but also includes BMI, which is used to assess nutritional status. ${ }^{21}$ BMI has always been considered a diagnostic criterion for nutrition. ${ }^{38}$ Among elderly community residents, a BMI of less than 22 was associated with a high 1-year mortality rate and poor functional status. ${ }^{39}$ Interestingly, previous studies have reported that BMI is associated with skeletal muscle reduction. ${ }^{32,40}$ For instance, Shibutani et al found a significant correlation between BMI and psoas muscle mass index (PMI). ${ }^{35}$ Albumin has been proven to predict the survival of patients with cancer cachexia and has been shown to indicate the severity of the disease. ${ }^{41,42}$ Systemic inflammation affects liver metabolism, stimulating an

Table 3 Survival Analysis of Different Risk Groups and Combination Analysis

\begin{tabular}{|c|c|c|c|c|}
\hline \multirow[t]{2}{*}{ Variables } & \multicolumn{2}{|c|}{ OS } & \multicolumn{2}{|c|}{ OS* } \\
\hline & Crude HR $(95 \% \mathrm{CI})$ & Crude $P$ & Adjusted HR (95\% Cl) & Adjusted $P$ \\
\hline Low-risk group & 1 & & 1 & \\
\hline High-risk group & $1.529(1.242-1.882)$ & $<0.001$ & $1.400(1.078-1.819)$ & 0.012 \\
\hline High ALI and low-risk group & I & & 1 & \\
\hline High ALI and High-risk group & $2.238(1.743-2.874)$ & $<0.001$ & $2.260(1.666-3.065)$ & $<0.001$ \\
\hline Low ALI and Low-risk group & $1.524(1.035-2.245)$ & 0.033 & $1.685(1.105-2.570)$ & 0.015 \\
\hline Low ALI and High-risk group & $2.973(2.242-3.943)$ & $<0.001$ & $3.095(2.085-4.592)$ & $<0.001$ \\
\hline
\end{tabular}

Notes: *Adjusted for age, sex and TNM stage; adjusted for age, sex, TNM stage, radical resection, postoperative chemoradiotherapy, ECOG PS, KPS, BMI, family history of cancer, tea consumption, alcohol consumption, smoking, diabetes, hypertension, coronary heart disease, AST, ALT, hemoglobin, serum total protein, serum albumin, WBC, lymphocytes, neutrophils, platelet, 30-day mortality, PGSGA, nutritional intervention.

Abbreviations: OS, overall survival; HR, hazards ratio; Cl, confidence interval; BMI, body mass index; ECOG PS, Eastern Cooperative Oncology Group Performance Status; KPS, Karnofsky Performance Status; AST, aspartate aminotransferase; ALT, alanine transaminase; WBC, white blood cells; ALI, advanced lung cancer inflammation index; NLR, neutrophil-lymphocyte ratio; PNI, prognostic nutritional index; SII, systemic immune-inflammation index; PLR, platelet-lymphocyte ratio; PGSGA, PatientGenerated Subjective Global Assessment. 


\begin{tabular}{|c|c|c|c|c|c|c|}
\hline \multirow[t]{2}{*}{ Variables } & \multirow{2}{*}{$\begin{array}{l}\text { High ALI }(\geq 25.03) \\
\text { Deaths/Patients }\end{array}$} & \multirow{2}{*}{$\begin{array}{c}\text { Low ALI }(<25.03) \\
\text { Deaths/Patients }\end{array}$} & & \multirow[t]{2}{*}{ Adjusted HR(95\%CI) } & \multirow[t]{2}{*}{ Adjusted $P$} & \multirow[t]{2}{*}{$P$ for interaction } \\
\hline & & & & & & \\
\hline Age (years) & & & & & & 0.187 \\
\hline$<70$ & $53 / 154$ & 95/151 & $\mathrm{Har}$ & $2.017(1.261-3.227)$ & 0.003 & \\
\hline$\geq 70$ & $78 / 185$ & $177 / 256$ & 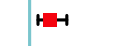 & $2.052(1.436-2.935)$ & $<0.001$ & \\
\hline Sex & & & & & & 0.143 \\
\hline Male & $89 / 213$ & $189 / 276$ & Hin & $1.790(1.268-2.526)$ & 0.001 & \\
\hline Female & $42 / 126$ & $83 / 131$ & $\mapsto$ & $2.840(1.706-4.726)$ & $<0.001$ & \\
\hline BMI $\left(\mathrm{kg} / \mathrm{m}^{\wedge} 2\right)$ & & & & & & 0.036 \\
\hline$<18.5$ & $34 / 68$ & $99 / 146$ & 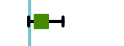 & $1.611(0.948-2.738)$ & 0.078 & \\
\hline $18.5-23.9$ & $69 / 201$ & $151 / 226$ & $H=-1$ & $2.002(1.383-2.899)$ & $<0.001$ & \\
\hline$>23.9$ & $28 / 70$ & $22 / 35$ & 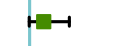 & $1.733(0.979-3.066)$ & 0.059 & \\
\hline Radical resection & & & & & & 0.618 \\
\hline No & $109 / 235$ & $226 / 296$ & $H$ & $2.172(1.602-2.946)$ & $<0.001$ & \\
\hline Yes & $22 / 104$ & $46 / 111$ & - & $1.457(0.861-2.466)$ & 0.161 & \\
\hline Postoperative chemoradiotherapy & & & & & & 0.090 \\
\hline No & $66 / 185$ & $135 / 236$ & $H$ & $1.492(0.983-2.267)$ & 0.06 & \\
\hline Yes & $65 / 154$ & $137 / 171$ & $H-1$ & $2.472(1.667-3.665)$ & $<0.001$ & \\
\hline TNM stage & & & & & & 0.455 \\
\hline I & $5 / 23$ & $2 / 27$ & & NA & NA & \\
\hline II & $18 / 82$ & 31/77 & $\longmapsto$ & $3.249(1.157-9.120)$ & 0.025 & \\
\hline III & 28/104 & $53 / 96$ & $\mapsto$ & $2.170(1.117-4.217)$ & 0.022 & \\
\hline IV & $\mathbf{8 0 / 1 3 0}$ & 180/207 & $r=-1$ & $2.242(1.559-3.225)$ & $<0.001$ & \\
\hline PGSGA & & & & & & 0.163 \\
\hline Well nourished & $20 / 65$ & $20 / 38$ & $\mapsto \longrightarrow$ & $1.600(0.493-5.188)$ & 0.434 & \\
\hline Moderately malnourished & $62 / 188$ & $130 / 213$ & $H$ & $2.339(1.549-3.532)$ & $<0.001$ & \\
\hline Severely malnourished & $49 / 86$ & $122 / 156$ & 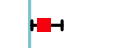 & $1.736(1.120-2.690)$ & 0.014 & \\
\hline Nutritional intervention & & & & & & 0.355 \\
\hline No & $101 / 260$ & $213 / 312$ & 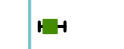 & $2.066(1.504-2.839)$ & $<0.001$ & \\
\hline Yes & $30 / 79$ & $59 / 95$ & 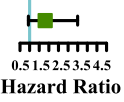 & $1.809(0.936-3.496)$ & 0.078 & \\
\hline
\end{tabular}

Figure 4 The stratification analysis of ALI in EPCC. Adjusted for age, sex, TNM stage, radical resection, postoperative chemoradiotherapy, ECOG PS, KPS, BMI, family history of cancer, tea consumption, alcohol consumption, smoking, diabetes, hypertension, coronary heart disease, AST, ALT, hemoglobin, serum total protein, serum albumin, WBC, lymphocytes, neutrophils, platelet, 30-day mortality, PGSGA, nutritional intervention.

Abbreviations: ALI, advanced lung cancer inflammation index; TNM stage, tumor-node-metastasis stage; WBC, white blood cells; AST, aspartate aminotransferase; ALT, alanine transaminase; BMI, body mass index; EORTC QLQ-C30, the European Organization for Research and Treatment of Cancer (EORTC), Quality of Life QuestionnaireCore 30 (QLQ-C30); PGSGA, Patient-Generated Subjective Global Assessment; KPS, Karnofsky Performance Status.

increase in acute phase protein production, while reducing albumin synthesis and increasing degradation. ${ }^{43}$ Therefore, hypoalbuminemia reflects a systemic inflammatory state and is influenced by systemic inflammatory response (SIR). ${ }^{44,45}$ SIR is deeply involved in various carcinogenesis and tumorigenesis through host-tumor interactions. The potential of SIR status as a prognostic marker of various cancers has also been confirmed, with NLR as a reliable SIR marker. ${ }^{46,47}$ NLR can explain the role of neutrophils in promoting inflammation and providing an appropriate environment for tumor growth by activating a variety of inflammatory markers. ${ }^{46}$ The lymphocyte count can also reflect the activation of the immune system and its inhibitory effect on tumor proliferation and migration. ${ }^{43}$ Since cancer cachexia is the result of chronic systemic inflammation, the combination of BMI and inflammatory markers can more accurately assess the prognosis of cancer cachexia and evaluate the degree of systemic inflammation.

In our study, we found that patients who satisfied the three diagnostic conditions of the 2011 Fearon Cancer Cachexia Diagnosis Consensus ${ }^{4}$ at the same time, namely 1) weight loss greater than $5 \%, 2$ ) BMI less than $20 \mathrm{~kg} / \mathrm{m} 2$ and weight loss greater than $2 \%$, and 3 ) 
sarcopenia and weight loss greater than $2 \%$, had a significantly higher risk of mortality than those who did not. When these high-risk patients had low ALI, the risk of mortality increased 3.028-fold. Unintended weight loss, low BMI, skeletal muscle reduction, and systemic inflammation are inevitable in elderly patients with cancer and are precursors of adverse consequences. If these conditions exist in EPCC at the same time, it will have an unfavorable additive effect on the prognosis of patients, which means that the treatment of these patients requires a more comprehensive strategy. On the contrary, another part of patients seems to be more likely to benefit from treatment. These factors pose a major challenge for healthcare providers in caring for elderly patients with cancer in the coming years. Given the multifaceted nature of these diseases, multimodal interventions are often associated with the best outcome. ${ }^{48}$

For the first time, the combined effects of inflammation in different EPCC populations was investigated, but the current research still has several limitations. First, this study aimed to explore the impact of systemic inflammation in EPCC, but it did not include other inflammatory indicators, such as CRP and IL-6. Compared with the indicators such as albumin used at this stage, the medical costs of CRP and IL- 6 are relatively high in China, but considering the value of these indicators, more inflammatory indicators need to be further included in this study in the future. Second, appropriate physical activity can improve sarcopenia and muscle atrophy typical of cachexia. Considering the particularity of EPCC, targeted physical activity measurement and evaluation tools and methods need to be developed. Third, this study did not involve a large study population. While increasing the number of samples, we need to pay more attention to homogeneous groups of patients, such as different stages and types of tumor. Fourth, some of the exclusion criteria in this study may cause some missing data on cachexia and cause selection bias. The cohort design should be further improved in the future. Finally, cancer cachexia is not entirely sarcopenia, distinguishing the difference between cachexia and sarcopenia is important for judging the patient's disease state. Additionally, to distinguish if the results reported are due to cancer or cachexia, a control/ comparator group without cachexia should be added.

\section{Conclusions}

In summary, the prognostic and discriminative value of the inflammatory indicator ALI was better than that of NLR, PNI,
SII, and PLR in EPCC. Whether ALI was used as a continuous variable or a categorical variable (binary and quarter), ALI had a better prognostic value in EPCC. Particularly, patients with low ALI $(<25.03)$ had a worse OS than patients with high ALI $(\geq 25.03)$. ALI might be an independent prognostic factor for EPCC. Notably, the high-risk group of EPCC with low ALI would significantly increase the mortality risk and OS. Effectively distinguish EPCCs with different prognostic statuses, so that different and targeted treatment strategies could be adopted more effectively.

\section{Data Sharing Statement}

The datasets used and analyzed during the current study are available from the corresponding author on reasonable request.

\section{Ethics Approval and Informed Consent}

This study followed the Helsinki declaration. All participants signed an informed consent form and this study was approved by the Institutional Review Board of each hospital (Registration number: ChiCTR1800020329).

\section{Acknowledgments}

We would like to thank Editage (www.editage.cn) for English language editing. We are grateful to all the participants who have been part of the project and to the many members of the study teams at different study centers who have enabled this research.

\section{Author Contributions}

All authors made a significant contribution to the work reported, whether that is in the conception, study design, execution, acquisition of data, analysis and interpretation, or in all these areas; took part in drafting, revising or critically reviewing the article; gave final approval of the version to be published; have agreed on the journal to which the article has been submitted; and agree to be accountable for all aspects of the work.

\section{Funding}

This work was supported by the National Key Research and Development Program [grant number 2017YFC1309200].

\section{Disclosure}

The authors report no competing interests in this work. 


\section{References}

1. Horstman AM, Sheffield-Moore M. Nutritional/metabolic response in older cancer patients. Nutrition. 2015;31(4):605-607.

2. Tisdale MJ. Cachexia in cancer patients. Nat Rev Cancer. 2002;2 (11):862-871.

3. Dunne RF, Loh KP, Williams GR, Jatoi A, Mustian KM, Mohile SG. Cachexia and sarcopenia in older adults with cancer: a comprehensive review. Cancers (Basel). 2019;11:12.

4. Fearon K, Strasser F, Anker SD, et al. Definition and classification of cancer cachexia: an international consensus. Lancet Oncol. 2011;12 (5):489-495.

5. Gould DW, Lahart I, Carmichael AR, Koutedakis Y, Metsios GS. Cancer cachexia prevention via physical exercise: molecular mechanisms. J Cachexia Sarcopenia Muscle. 2013;4(2):111-124.

6. Baracos VE, Martin L, Korc M, Guttridge DC, Fearon KC. Cancerassociated cachexia. Nat Rev Dis Primers. 2018;4:17106.

7. Fearon KC, Voss AC, Hustead DS; Cancer Cachexia Study G. Definition of cancer cachexia: effect of weight loss, reduced food intake, and systemic inflammation on functional status and prognosis. Am J Clin Nutr. 2006;83(6):1345-1350.

8. Argiles JM, Busquets S, Stemmler B, Lopez-Soriano FJ. Cancer cachexia: understanding the molecular basis. Nat Rev Cancer. 2014;14(11):754-762.

9. Stephens NA, Skipworth RJ, Fearon KC. Cachexia, survival and the acute phase response. Curr Opin Support Palliat Care. 2008;2 (4):267-274.

10. Goncalves RC, Freire PP, Coletti D, Seelaender M. Tumor microenvironment autophagic processes and cachexia: the missing link? Front Oncol. 2020;10:617109.

11. Sharma K, Mogensen KM, Robinson MK. Pathophysiology of critical illness and role of nutrition. Nutr Clin Pract. 2019;34(1):12-22.

12. Proctor MJ, Morrison DS, Talwar D, et al. An inflammation-based prognostic score (mGPS) predicts cancer survival independent of tumour site: a Glasgow Inflammation Outcome Study. Br J Cancer. 2011;104(4):726-734.

13. Argiles JM. The 2015 ESPEN Sir David Cuthbertson lecture: inflammation as the driving force of muscle wasting in cancer. Clin Nutr. 2017;36(3):798-803.

14. Argiles JM, Stemmler B, Lopez-Soriano FJ, Busquets S. Inter-tissue communication in cancer cachexia. Nat Rev Endocrinol. 2018;15 (1):9-20.

15. Thomas DR. Loss of skeletal muscle mass in aging: examining the relationship of starvation, sarcopenia and cachexia. Clin Nutr. 2007;26(4):389-399.

16. Espat NJ, Moldawer LL, Copeland EM 3rd. Cytokine-mediated alterations in host metabolism prevent nutritional repletion in cachectic cancer patients. J Surg Oncol. 1995;58(2):77-82.

17. Murray S, Schell K, McCarthy DO, Albertini MR. Tumor growth, weight loss and cytokines in SCID mice. Cancer Lett. 1997;111(12):111-115.

18. Haddad F, Zaldivar F, Cooper DM, Adams GR. IL-6-induced skeletal muscle atrophy. J Appl Physiol. 2005;98(3):911-917.

19. Nitenberg G, Raynard B. Nutritional support of the cancer patient: issues and dilemmas. Crit Rev Oncol Hematol. 2000;34(3):137-168

20. Jomrich G, Paireder M, Kristo I, et al. High systemic immune-inflammation index is an adverse prognostic factor for patients with gastroesophageal adenocarcinoma. Ann Surg. 2021;273(3):532-541.

21. Yin C, Toiyama Y, Okugawa $Y$, et al. Clinical significance of advanced lung cancer inflammation index, a nutritional and inflammation index, in gastric cancer patients after surgical resection: a propensity score matching analysis. Clin Nutr. 2021;40(3):1130-1136.

22. Okadome K, Baba Y, Yagi T, et al. Prognostic nutritional index, tumor-infiltrating lymphocytes, and prognosis in patients with esophageal cancer. Ann Surg. 2020;271(4):693-700.
23. Chakiryan NH, Kimmel GJ, Kim Y, et al. Geospatial cellular distribution of cancer-associated fibroblasts significantly impacts clinical outcomes in metastatic clear cell renal cell carcinoma. Cancers (Basel). 2021;13:15.

24. Guo ZQ, Yu JM, Li W, et al. Survey and analysis of the nutritional status in hospitalized patients with malignant gastric tumors and its influence on the quality of life. Support Care Cancer. 2020;28 (1):373-380.

25. Hanahan D, Coussens LM. Accessories to the crime: functions of cells recruited to the tumor microenvironment. Cancer Cell. 2012;21 (3):309-322.

26. Maccio A, Sanna E, Neri M, Oppi S, Madeddu C. Cachexia as evidence of the mechanisms of resistance and tolerance during the evolution of cancer disease. Int J Mol Sci. 2021;22:6.

27. Ferrucci L, Fabbri E. Inflammageing: chronic inflammation in ageing, cardiovascular disease, and frailty. Nat Rev Cardiol. 2018;15 (9):505-522.

28. Mandaliya H, Jones M, Oldmeadow C, Nordman II. Prognostic biomarkers in stage IV non-small cell lung cancer (NSCLC): neutrophil to lymphocyte ratio (NLR), lymphocyte to monocyte ratio (LMR), platelet to lymphocyte ratio (PLR) and advanced lung cancer inflammation index (ALI). Transl Lung Cancer Res. 2019;8 (6):886-894

29. Qi WX, Xiang Y, Zhao S, Chen J. Assessment of systematic inflammatory and nutritional indexes in extensive-stage small-cell lung cancer treated with first-line chemotherapy and atezolizumab. Cancer Immunol Immunother. 2021;70(11):3199-3206.

30. Topkan E, Ozdemir Y, Kucuk A, et al. Low advanced lung cancer inflammation index predicts poor prognosis in locally advanced nasopharyngeal carcinoma patients treated with definitive concurrent chemoradiotherapy. J Oncol. 2020;2020:3127275.

31. Gaudioso P, Borsetto D, Tirelli G, et al. Advanced lung cancer inflammation index and its prognostic value in HPV-negative head and neck squamous cell carcinoma: a multicentre study. Support Care Cancer. 2021;29:1-9.

32. Tan X, Peng H, Gu P, Chen M, Wang Y. Prognostic significance of the L3 skeletal muscle index and advanced lung cancer inflammation index in elderly patients with esophageal cancer. Cancer Manag Res. 2021;13:3133-3143.

33. Demirelli B, Babacan NA, Ercelep O, et al. Modified Glasgow prognostic score, prognostic nutritional index and ECOG performance score predicts survival better than sarcopenia, cachexia and some inflammatory indices in metastatic gastric cancer. Nutr Cancer. 2021;73(2):230-238.

34. Kusunoki K, Toiyama Y, Okugawa Y, et al. Advanced lung cancer inflammation index predicts outcomes of patients with colorectal cancer after surgical resection. Dis Colon Rectum. 2020;63 (9):1242-1250.

35. Shibutani M, Maeda K, Nagahara $\mathrm{H}$, et al. The prognostic significance of the advanced lung cancer inflammation index in patients with unresectable metastatic colorectal cancer: a retrospective study. BMC Cancer. 2019;19(1):241.

36. Cheng X, Dong Y, Lou F. The predictive significance of the Advanced Lung Cancer Inflammation Index (ALI) in patients with melanoma treated with immunotherapy as second-line therapy. Cancer Manag Res. 2021;13:173-180.

37. Park YH, Yi HG, Lee MH, Kim CS, Lim JH. Prognostic value of the pretreatment Advanced Lung Cancer Inflammation Index (ALI) in diffuse large B cell lymphoma patients treated with R-CHOP chemotherapy. Acta Haematol. 2017;137(2):76-85.

38. Cederholm T, Bosaeus I, Barazzoni R, et al. Diagnostic criteria for malnutrition - An ESPEN Consensus Statement. Clin Nutr. 2015;34 (3):335-340.

39. Landi F, Zuccala G, Gambassi G, et al. Body mass index and mortality among older people living in the community. $J \mathrm{Am}$ Geriatr Soc. 1999;47(9):1072-1076. 
40. Kim EY, Kim YS, Park I, Ahn HK, Cho EK, Jeong YM. Prognostic significance of CT-determined sarcopenia in patients with small-cell lung cancer. J Thorac Oncol. 2015;10(12):1795-1799.

41. Utech AE, Tadros EM, Hayes TG, Garcia JM. Predicting survival in cancer patients: the role of cachexia and hormonal, nutritional and inflammatory markers. J Cachexia Sarcopenia Muscle. 2012;3 (4):245-251.

42. Gray S, Axelsson B. The prevalence of deranged C-reactive protein and albumin in patients with incurable cancer approaching death. PLoS One. 2018;13(3):e0193693.

43. Fearon KC, Barber MD, Falconer JS, McMillan DC, Ross JA, Preston T. Pancreatic cancer as a model: inflammatory mediators, acute-phase response, and cancer cachexia. World J Surg. 1999;23 (6):584-588.
44. Moshage HJ, Janssen JA, Franssen JH, Hafkenscheid JC, Yap SH. Study of the molecular mechanism of decreased liver synthesis of albumin in inflammation. J Clin Invest. 1987;79(6):1635-1641.

45. Evans DC, Corkins MR, Malone A, et al. The use of visceral proteins as nutrition markers: an ASPEN position paper. Nutr Clin Pract. 2021;36(1):22-28

46. Singh R, Mishra MK, Aggarwal H. Inflammation, immunity, and cancer. Mediators Inflamm. 2017;2017:6027305.

47. Colotta F, Allavena P, Sica A, Garlanda C, Mantovani A. Cancerrelated inflammation, the seventh hallmark of cancer: links to genetic instability. Carcinogenesis. 2009;30(7):1073-1081.

48. Fearon KC. Cancer cachexia: developing multimodal therapy for a multidimensional problem. Eur J Cancer. 2008;44(8):1124-1132.
Journal of Inflammation Research

\section{Publish your work in this journal}

The Journal of Inflammation Research is an international, peerreviewed open-access journal that welcomes laboratory and clinical findings on the molecular basis, cell biology and pharmacology of inflammation including original research, reviews, symposium reports, hypothesis formation and commentaries on: acute/chronic inflammation; mediators of inflammation; cellular processes; molecular
Dovepress

mechanisms; pharmacology and novel anti-inflammatory drugs; clinical conditions involving inflammation. The manuscript management system is completely online and includes a very quick and fair peerreview system. Visit http://www.dovepress.com/testimonials.php to read real quotes from published authors. 